\title{
La génesis del mito anti-español de la masonería en los años de la restauración borbónica (1874-1923) ${ }^{1}$
}

\author{
The Origins of the Anti-Spanish Myth of Freemasonry in the Years \\ of the Bourbon Restoration (1874-1923)
}

\author{
Sergio Ceballos Coz \\ Universidad de Cantabria, España \\ sergioceballos81@gmail.com
}

Recepción: 13 de abril de 2019/Aceptación: 22 de mayo de 2019.

doi: https://doi.org/10.15517/rehmlac.v11i1.36038

Palabras clave

España, Restauración, masonería, política, mito.

Keywords

Spain, Restoration, Freemasonry, Politics, Myths.

\section{Resumen}

Aunque el mito anti-español de la masonería se consolida oficiosamente al final de la Guerra Civil con la promulgación, por parte del nuevo Jefe de Estado Francisco Franco, de la famosa Ley para la Represión de la Masonería y el Comunismo fechada el 1 de marzo de 1940, lo cierto es que ya desde finales del siglo XIX la Orden del Gran Arquitecto del Universo hispana va a verse identificada por medios de comunicación, políticos e Iglesia Católica, como uno de los agentes principales que pretenden acabar con España, ya fuera en el plano religioso, con la supuesta persecución de todo lo relacionado con el catolicismo, o en el político y territorial, al ser acusada de intentar derribar la monarquía constitucional y de provocar el Desastre de 1898, suceso que supuso la pérdida de los últimos vestigios coloniales imperiales.

\begin{abstract}
Although the anti-Spanish myth of Freemasonry is informally consolidated at the end of the Spanish Civil War with the promulgation of the famous Law for the Repression of Freemasonry and Communism on March $1^{\text {st }}$ 1940, by the new Head of State, Francisco Franco, the truth is that since the end of the 19th century the Order of the Great Architect of the Universe was identified by the media, politicians and the Catholic Church, as one of the main agents that intend to put an end to Spain. Whether on the religious arena, with the supposed persecution of everything related to Catholicism, or in the political and imperial arena as, during the time when Freemasonry was accused of trying to overthrow the constitutional monarchy and provoke the Disaster of 1898 , an event that meant the loss of Spain's last imperial vestiges.
\end{abstract}

\footnotetext{
${ }^{1}$ El siguiente texto es una versión corregida de uno de los apartados de nuestro trabajo de fin de grado cuyo título es La masonería en la España de la Restauración (1874-1923): un reto entre libertad, progreso, democracia y rechazo. Fue presentado el 24 de septiembre de 2018 ante tribunal público constituido por profesores doctores de los departamentos de Ciencias Históricas e Historia Moderna y Contemporánea de la Facultad de Filosofía y Letras de la Universidad de Cantabria, obteniendo la calificación de sobresaliente.
} 


\section{Introducción}

El 1 de noviembre de 1936 tenía lugar en la ciudad de Burgos, epicentro del gobierno sublevado contra la Segunda República, una conferencia pronunciada por el sacerdote católico Juan Tusquets, considerado por los historiadores como el principal propagandista antijudeo-masónico español de todos los tiempos ${ }^{2}$. La temática abordada en aquel seminario, publicada más tarde a modo de libelo con el título La Francmasonería, Crimen de Lesa Patria, presentaba a la Orden del Gran Arquitecto del Universo como símbolo principal de la religión laica, dispuesta a minar en toda su esencia el predominio de la confesión católica pues no hacía sino servir a los planes del "imperialismo inglés", lugar dónde precisamente había nacido la masonería especulativa en el siglo XVIII ${ }^{3}$.

El autor, prolífico catalanista y revolucionario en su juventud, cambió su forma de ver a las izquierdas y a las asociaciones secretas, entre ellas la masonería, después de ordenarse clérigo en $1926^{4}$. Fruto de esa aversión, y entendiendo el contexto de guerra que se atravesaba en España a finales del año 1936, florecía uno de los tópicos más extendidos durante el franquismo resultante a la salida la contienda: la masonería, por su asociación con judíos y comunistas, no solo pretendía acabar con la religión católica, sino que también quería acabar con España, aquella nación que representaba la defensa del catolicismo desde el Concilio de Trento 5 . Del mismo modo, y para mayor consagración del mito, la Orden había sido, en palabras de Tusquets, la principal causante de que se diera en 1789 una revolución como la francesa, "negación del verdadero patriotismo", al arruinar y desangrar al país galo de la forma en que lo hizo ${ }^{6}$.

Aunque la alocución está divida en varias partes, nos interesa aquí destacar aquella que se refiere a España, titulada en la publicación posterior con el llamativo Cinco años de la Revolución Francmasónica. La República, régimen político llegado al país en 1931, era el resultado, según el clérigo, de las muchas conspiraciones llevadas a cabo por los masones en los años de la Restauración y la Dictadura de Primo de Rivera, pues estos, con sus actividades clandestinas, lo único que pretendían era "apoderarse de los resortes universales de poder", algo conseguido con la caída de la monarquía. Y no solo eran los "hijos de la viuda" los responsables del auge del republicanismo en el inicio de la década de los años treinta: también tenían la culpa de todos los males acaecidos en el periodo, como el Estatuto de Cataluña, los sucesos revolucionarios de 1934 o la reciente muerte del líder de Renovación Española José

\footnotetext{
2 Javier Domínguez Arribas, "Juan Tusquets y sus ediciones antisectarias (1936-1939)", en La masonería española en la época de sagasta, coord. José Antonio Ferrer Benimeli (Zaragoza: CEHME, 2007), tomo II, 1157.

${ }^{3}$ Juan Tusquets, La francmasonería, crimen de lesa patria (Burgos: Ediciones Antisectarias, 1936), 7.

${ }^{4}$ Paul Preston, El holocausto español: odio y exterminio en la guerra civil y después (Barcelona: Debate, 2017), 71.

${ }^{5}$ José Álvarez Junco, Mater dolorosa, la idea de España en el siglo XIX (Barcelona: Taurus, 2001), 308-318.

${ }^{6}$ Tusquets, La francmasonería, 11.
} 
Calvo Sotelo ${ }^{7}$. El mejor ejemplo de que todas las iniciativas políticas habidas en España eran masónicas lo representaba la figura del jefe del Estado, Manuel Azaña, principal cabeza visible de la República. Aunque el autor es consciente de la casi nula actividad masónica del presidente ${ }^{8}$, no deja de alertar a sus lectores de la posibilidad de que éste tenga altos cargos en la masonería mundial con los cuales socavar el país ${ }^{9}$, algo de lo que Azaña carecía rotundamente.

En última instancia, al final de su relato, atacaba Tusquets al Gran Oriente Español (GOE), la principal obediencia masónica española desde finales del siglo XIX, organismo responsable de todas las acciones masónicas al educar a sus miembros "por negocio, por vanidad", siendo, además, el órgano dependiente de una Gran Logia Nacional "juguete de Moscú". Lejos de interpretar las palabras del sacerdote como falsas o verídicas, aunque los historiadores han demostrado que muestran poca evidencia de verdad, debemos quedarnos con lo que suponía ser masón al comienzo de la Guerra Civil y eminentemente al final de la misma. Juzgado por el Tribunal para la Represión de la Masonería y el Comunismo, organismo creado mediante legislación por el Movimiento en 1940, aquel vencedor en la "cruzada", pasaba a ser considerado un criminal contra la patria y la religión al haber intervenido contra la tradición religiosa española y en todos los males patrios desde el inicio del derrumbe imperial en el siglo $\mathrm{XIX}^{10}$. De ahí que Tusquets recomendara en su texto al Generalísimo Franco la prohibición de llevar a cabo "juramento de lealtad a España" todo afín a la masonería en el "Nuevo Estado" regido "sobre la ley de Dios" salido de la guerra" Ser masón era, en una palabra, formar parte de la Anti-España ${ }^{12}$.

De cómo comienza a crearse este mito de anti-españolidad de la masonería, cuyo origen puede vislumbrarse en el periodo histórico que estamos abordando, es decir, en la restauración monárquica, y la reiterada defensa que hacen los masones contra tales acusaciones, trataremos a lo largo de las siguientes páginas.

\section{Las condenas papales en tiempos de reorganización interna}

Después de que a luz de la Revolución Gloriosa de 1868 llegase de una forma oficial la institución masónica a España debido a haber ocupado muchos masones ilustres carteras ministeriales, e incluso la primera jefatura del gobierno del nuevo régimen recaída en Juan

\footnotetext{
7 Tusquets, La francmasonería, 19.

${ }^{8}$ En sus diarios podemos apreciar la escasa importancia que daba el líder republicano a las tenidas masónicas, reflejando, en la única a la que asistió por motivo de su iniciación, un aburrimiento que a punto estuvo de hacerlo abandonar el lugar donde se estaba realizando. Manuel Azaña Díaz, Memorias políticas y de guerra (Barcelona: Crítica, 1981), 421.

9 Tusquets, La francmasonería, 19.

${ }^{10}$ Boletín Oficial del Estado [BOE], "Ley de 1 de Marzo de 1940 Sobre Represión de la Masonería y del Comunismo", no. 62 (Madrid, 1 de marzo de 1940): 1537-1539.

11 Tusquets, La francmasonería, 50-52.

12 Para una correcta interpretación del significado de tal concepto, véase Santos Juliá, Historias de las dos Españas (Madrid: Taurus, 2004), 287-293.
} 
Prim y Prats, lo cierto es que a la Orden le iba a ser inevitable verse afectada por los acontecimientos políticos del momento. Aunque a la proclamación del Sexenio Democrático los masones existentes en las Cortes Constituyentes de 1869 eligieron decantarse por la candidatura de Amadeo de Saboya al trono del país, éstos se verían fuertemente contrariados en el momento de proclamarse la solución republicana en 1873 ante la inoperatividad y falta de apoyos encontrada en la real persona de quien había sido máximo representante del Estado durante poco más de dos años. La Primera República, primer ensayo de este signo en la historia española, había llegado con mucha prevención desde el campo masónico; el Gran Oriente de España (GODE), obediencia sin duda influyente por aquel tiempo junto con el Gran Oriente Nacional de España (GONE), proclamaba su neutralidad política habida cuenta del gran número de masones entre sus filas participes de la monarquía ${ }^{13}$. Pesaba sobre tal decisión el hecho de ser defensor de una masonería de tipo "regular", es decir, con logias nada afines a la intervención en los asuntos políticos y bastante rigurosas con los principios establecidos en las Constituciones de Anderson de $1723^{14}$.

La llegada de la Restauración, constructo político diseñado por Cánovas del Castillo, lejos de resultar fructífero para el campo masónico en sus primeros tiempos, contribuyó a elevar las disensiones dentro de la Orden. Si en el pasado los masones habían gozado de un relevante asociacionismo fruto del ordenamiento constitucional de 1869, la sanción de una nueva Constitución en 1876, aunque reconocía la tolerancia hacia otras religiones en su artículo 11, dejaba el derecho de asociación de los españoles en lo así dispuesto en el Código Penal de $1870^{15}$. Si hasta antes de la nueva Carta Magna éste establecía la pena de prisión para los miembros de todas aquellas sociedades cuyos estatutos no se hubiesen hecho públicos, una vez aprobado el texto constitucional el articulado del ordenamiento penal quiso sufrir bruscos cambios que iban atacar a sociedades como la masonería. Serían presentados varios proyectos de reforma penal, como el del político conservador Gabino Bugallal, proponiéndose un severo cambio en los artículos 236 al 241 y 189 al 203, para que, además de castigarse la formación templos sin la previa autoridad gubernamental, se condenara a prisión a todas aquellas personas actuantes en sectas que "se valieran de cifras, jeroglíficos y otros signos misteriosos" y negasen la entrada en ellas a la autoridad y sus agentes ${ }^{16}$. Aunque el proyecto quedó solo en eso, la situación con respecto a la legalidad de las instituciones masónicas seguirá el mismo curso hasta la aprobación de la Ley de Asociaciones de 1887, fruto de los aires liberales del gobierno de Sagasta, quién, para entonces, y dicho sea de paso, ya había abandonado la masonería. Obediencias como el GONE, el GODE y el Gran Oriente

\footnotetext{
${ }^{13}$ Ángel Duarte, El republicanismo, una pasión politica, (Madrid: Ediciones Cátedra, 2013), 97.

${ }^{14}$ Javier Alvarado Planas, Masones en la nobleza de España, una hermandad de iluminados (Madrid: La Esfera de los Libros, 2016), 26-27.

${ }^{15}$ Victoria Hidalgo Nieto, "Masonería y libertad de asociación”, en La masonería en la España del siglo XIX, coord. Ferrer Benimeli (Salamanca: CEHME, 1987), tomo II, 416.

${ }^{16}$ Ferrer Benimeli, "Práxedes Mateo-Sagasta, gran maestre de la masonería", en La masonería española en la época de sagasta, coord. Ferrer Benimeli (Zaragoza, CEHME, 2007), tomo I, 26-27.
} 
Lusitano Unido (GOLU), además de muchas logias adscritas a éstas y otras familias, oficializaban su solicitud para constituirse como asociación con respecto a la ley ${ }^{17}$. Lo hacían, sin embargo, con mucha cautela, presentándose como sociedades humanitarias, científicas, benéficas y de progreso universal ${ }^{18}$, sin que la terminología "sociedad masónica" apareciera por ningún lugar ${ }^{19}$. Si bien, aunque la mayoría de todas estas obediencias obtuvieron carta blanca para constituirse, asociarse y cumplir la legalidad, lo cierto es que no se reconocía con su aprobación la existencia legal de la masonería en España, pues las distintas Órdenes aparecidas, aunque eran a toda luz masónicas, no constaba ello en sus registros administrativos. Pero, además, tampoco debemos olvidar la vigencia del Código Penal de 1870, aquel dispuesto a perseguir a toda sociedad cuyos estatutos no estuviesen en conocimiento de la administración, pues estaría vigente más de medio siglo ${ }^{20}$. Existían, por tanto, las obediencias masónicas y sus respectivas logias, pero no un cuerpo masónico reglado y respetado por el Estado que sin duda afectará, junto con otros factores, al reconocimiento de la masonería española en el plano internacional. Sea como fuere, ninguna duda cabe del despegue del universo masónico en la mayoría del territorio nacional, tanto en la metrópoli como en las colonias, desde 1868 hasta 1900, con la aparición de, al menos, 1750 logias ubicadas, en su inmensa mayoría, por los distintos territorios de Andalucía y Cataluña ${ }^{21}$.

Al margen de los problemas de legalidad sufridos por la familia masónica hasta la Ley de Asociaciones de 1887, resulta imposible no reseñar en este apartado las numerosas condenas papales existentes en el periodo contra la masonería, al entender los pontífices que su sola existencia era un peligro para la pervivencia del catolicismo. Dictada la primera condena internacional contra la Orden del Gran Arquitecto del Universo en la carta apostólica de Clemente XII In eminenti el 28 de abril de $1738^{22}$, época en la que no existía nada más que una logia activa en España, la "Matritense" ${ }^{\circ}$ 50, los sucesivos Papas que le devinieron no hicieron sino reiterar condenas de sus antecesores en el cargo. Por ello, nos centraremos en esta exposición en el episcopado monárquico de Vincenzo Gioacchino Raffaele Luigi

\footnotetext{
${ }^{17}$ Los representantes de las distintas instituciones masónicas debían presentar a la administración, ocho días antes de ser constituidas, los estatutos, reglamentos, lugar de domicilio y recursos con los que contaban para así recibir el visto bueno. Gaceta de Madrid, "Ley de Asociaciones de 1887", 12 de julio de 1887.

${ }^{18}$ Víctor Manuel Arbeloa, Clericalismo y anticlericalismo en España (1767-1930): una introducción (Madrid: Encuentro, 2009), 311. Así lo hizo el Gran Oriente Nacional de España en julio de 1887. Véase Alvarado Planas, Masones en la nobleza de España, 230.

${ }^{19}$ Quizá la única referencia explícita como organización masónica fue la llevada a cabo por José María Pantoja en 1889, presentando la escisión del Grande Oriente Nacional de España no integrada en el Gran Oriente Español de Morayta en el registro de asociaciones como "antiquísima Asociación francmasónica". Véase Hidalgo Nieto, "Masonería y libertad", 422.

${ }^{20}$ José Antonio Escudero, "Las sociedades secretas ante la legislación española del siglo XIX", en Masonería, política y sociedad, coord. Ferrer Benimeli (Zaragoza: CEHME, 1989), tomo II, 539.

${ }^{21}$ Víctor Manuel Arbeloa, Clericalismo y anticlericalismo, 311-312.

${ }^{22}$ Ferrer Benimeli, La masonería actual (Barcelona: AHR, 1977), 25.
} 
Pecci, ordenado Papa de la Iglesia Católica bajo el nombre de León XIII en 1878, manteniéndose en el cargo hasta su fallecimiento en 1903.

Considerado por el intelectual y político republicano Luis de Zulueta como "un enamorado de la Edad Media, enemigo de las novedades, y obsesionado con la masonería y el demonio" "23, León XIII será, junto con su antecesor Pío IX, el máximo perseguidor de las sociedades secretas, habida cuenta de las más de 2000 intervenciones de ambos pontífices contra ellas. Entre las mismas destacaba la masonería, a la cual acusaban de provocar la Unificación de Italia y recluir de ese modo a los jerarcas de la Iglesia como "cautivos en Roma"24. Si las mayores obras del pontificado de Pío IX habían sido la promulgación de la encíclica Quanta Cura y el famoso Syllabus Errorum en 1864, por las cuales el Papa realizaba una declaración de guerra a la sociedad moderna condenando "ochenta errores políticos, filosóficos y religiosos" entre los que estaba la masonería y también ideologías políticas como liberalismo y socialismo ${ }^{25}$, León XIII iba a proceder en 1884 con una encíclica solo destinada a condenar a la masonería, siendo ésta la acusación más dura vista por la Orden en todos sus años de Historia ${ }^{26}$.

Titulada Humanum Genus, comienza recordando las reiteradas condenas papales contra la institución desde 1738, así como las llevadas a cabo por ciertos gobiernos nacionales, entre los que nombra a la propia España. Señala más tarde el motivo de la persecución contra la Orden: su "naturaleza maléfica", por lo que era prioritario impedir el contagio de tan grande enfermedad, nacida "por la envidia de Lucifer"27. La dureza del texto, fruto de la enemistad del papado contra una Orden que supuestamente pretendía aniquilar el catolicismo y la moral imperante, vendría a señalar, tal y como ha constatado Manuel Suárez Cortina, la formación de "dos universos antagónicos, el de la religión y el de la masonería" 28 , siendo representante del último los círculos republicanos, demócratas laicistas y librepensadores, enemigos de la religión que trabajan al auxilio del "reino de Satanás".

La resonancia de tales proclamas papales no tardó en llegar a España, país muy sensible a todo lo relacionado con el catolicismo desde la Edad Media y muy especialmente, en el inicio de la contemporaneidad, desde la Constitución de 1812, aquella que señalaba la confesionalidad de la nación, y la firma del Concordato de 1851. Prelados como Sánchez de Castro, Obispo de Santander, escasos años después de la promulgación de la famosa

\footnotetext{
${ }^{23}$ Luis de Zulueta, La oración del incrédulo: ensayos sobre el problema religioso (Madrid: Biblioteca Nueva, 1915), 82.

${ }^{24}$ Víctor Manuel Arbeloa, Clericalismo y anticlericalismo, 312-313.

${ }^{25}$ Ferrer Benimeli, "El krausoinstitucionismo, la masonería y el librepensamiento", en Libertad, armonía y tolerancia: la cultura institucionista en la España contemporánea, coord. Manuel Suárez Cortina (Madrid: Tecnos, 2011), 314-320.

${ }^{26}$ Manuel Suárez Cortina, El gorro frigio: liberalismo, democracia y republicanismo en la restauración (Madrid: Sociedad Menéndez Pelayo, 2000), 191.

${ }^{27}$ Encíclica Humanum Genus, (Vaticano, 20 de abril de 1884).

${ }^{28}$ Suárez Cortina, Entre cirios y garrotes: política y religión en la España contemporánea, 1808-1936 (Santander: Universidad de Cantabria, 2014), 162.
} 
encíclica, trataba la masonería como sinónimo de revolución, dispuesta a actuar "contra las monarquías", cuyo objetivo principal era "perseguir y anonadar la Religión Católica"22. Esta será solo una de las muchas sacudidas en las que se verá inmiscuida la masonería, iniciándose así un "combate" entre los sectores más afines a la religión, partidarios de la catolicidad del país, como el carlismo, el integrismo y ciertos sectores del conservadurismo, y, por otro lado, el republicanismo, el anticlericalismo y librepensamiento, defensores acérrimos de la separación Iglesia-Estado, quienes harán causa común con la Orden debido a la filiación de muchos hermanos en los tres movimientos, otorgando un claro clima de rivalidad a la España de fines del siglo XIX ${ }^{30}$. Todos ellos, de uno u otro signo, no dudarán en hacer oposición al régimen constituido, pero la perdurabilidad de los segundos en el tiempo, además de consolidarlos como principales opositores, les hará constituirse como la principal alternativa gubernamental cuándo la crisis final de la monarquía desacredite su continuidad en el futuro debido a sus actos en el pasado.

Casualidad o no, al mismo tiempo que el prelado santanderino acusaba a la Orden de combatir el régimen monárquico, nacía, en 1889, el GOE, defensor de una ideología claramente republicana, cuyo líder principal, Miguel Morayta, señalaba como unas de las principales razones de ser de la masonería el combate contra el fanatismo religioso ${ }^{31}$. Entraba de lleno el Gran Arquitecto del Universo, a fuer de defenderse, en una lucha que no le deparará buen final.

\section{La prensa integrista ataca a la Orden: el debate en torno a la iniciación masónica de los Reyes de España.}

El verano de 1894 fue un periodo difícil y turbulento para el universo masónico español, quizá premonitorio con lo que iba a ocurrir escasos cuatro años después. Gobernaba el país en aquel momento el joven monarca Alfonso XIII, retraído de ser la figura de Jefe de Estado debido a su minoría de edad, pues contaba entonces con apenas ocho años, recayendo el papel de máximo representante del país en su madre María Cristina de Habsburgo-Lorena, regente del reino hasta 1902, tiempo en el que demostró ser una monarca muy capaz pero no por ello carente de críticas, teniéndose que enfrentar durante la infancia de su hijo a numerosas crisis $^{32}$.

Una de ellas comenzó en aquel verano al verse ella y su primogénito acusados de iniciarse en la masonería. La noticia fue difundida en prensa en el semanario católico $L a$ Hormiga de Oro, dirigido por el político y periodista Luis María de Llauder y defensor de

\footnotetext{
29 Julio de la Cueva Merino, Clericales y anticlericales: el conflicto entre confesionalidad y secularización (1875-1923) (Santander: Universidad de Cantabria, 1994), 188.

${ }^{30}$ Suárez Cortina, El gorro frigio, 160-161.

${ }^{31}$ La Luz de la Verdad, 30 de agosto de 1891, 1.

32 Morgan C. Hall, Alfonso XIII y el ocaso de la monarquía liberal, 1902-1923 (Madrid: Alianza Editorial, 2005), 36 .
} 
una ideología puramente integrista ${ }^{33}$. Para evitar tener problemas con la justicia, pues podía ser tomada la afirmación como un delito de calumnias contra los representantes del Estado, Llauder atribuyó sus palabras al párroco José Domingo Corbató, autor de una obra publicada en Valencia ese mismo año con el título León XIII, Los Carlistas y La Monarquía Federal. La táctica seguida por el periodista, además de intentar librar a su persona de cualquier compromiso con la ley, tenía una razón principal de ser: el desprestigio de la monarquía y de su principal cabeza, la regente María Cristina, habida cuenta de los buenos lazos existentes entre ésta y el Papa León XIII, pues si el segundo, con sus peregrinaciones a España, había mostrado el respeto debido por el país y sus líderes, la regente estaba atacando duramente al Obispado de Roma, cabeza de la Cristiandad, al haberse iniciado en una "secta" prohibida por la religión y combatida principalmente por el propio pontífice en el cargo, como ya hemos visto $^{34}$.

Aunque es difícil saber si tal acusación causó malas relaciones entre los representantes de la Iglesia y de España, lo cierto es que la noticia, aunque falsa, no dejaría de correr por la mayoría de los medios nacionales y provinciales. El gobierno del país, con Sagasta a la cabeza, señalaba la falsedad de la proclama ante el gran revuelo mediático. Ello llevó a que el referido líder del GOE y principal cabeza de la masonería española, Miguel Morayta, censurase mediante carta envidada a todas las logias de su obediencia la actuación del gobierno, remitida más tarde al ministerio de Gracia y Justicia ${ }^{35}$. Además de señalar la falta de verdad en la iniciación de los monarcas, Morayta refería en su texto el repudio que indirectamente lanzaba el gobierno contra la masonería, condenando en el plano moral lo aprobado y otorgado en el político con la promulgación de la Ley de Asociaciones, cuerpo legal en el cual los masones se hallaban acogidos. El Gran Maestre, con el objetivo de defenderse, no solo no veía nada malo en la existencia de la masonería, sino que hablaba de ella con orgullo: "el consejo de la Orden de mi presidencia, como los muchos miles de masones a quienes represento, le llevan y le llevarán (el título de masón) con dignidad, seguros de que nos enaltece" 36 .

La actuación del gobierno, tajante con respecto a la falsedad de los hechos pero reprobada por la élite masónica con respecto a las formas, no fue suficiente para evitar que el debate llegase a las Cortes. En la sesión del 14 de noviembre de 1894, tomaba la palabra el diputado conservador por Cartagena Antonio García Alix, firme defensor del poder y prestigio de la realeza ${ }^{37}$. Haciendo alarde de sus "fervores dinásticos", como más tarde

\footnotetext{
33 Jordi Canal, "Los instrumentos del infierno: masonería y judaísmo en la prensa carlista a finales del siglo XIX", en La masonería española en la época de sagasta, coord. Ferrer Benimeli (Zaragoza: CEHME, 2007), tomo I, 60.

${ }^{34}$ Canal, "Los instrumentos del infierno", 61.

${ }^{35}$ Para un mayor acercamiento a las palabras del Miguel Morayta, véase el Boletín Oficial del Grande Oriente Español [BOGOE], no. 100 (Madrid, noviembre de 1894).

${ }^{36}$ Citado en Ferrer Benimeli, "Práxedes Mateo-Sagasta", 33-35.

${ }^{37}$ Javier Tusell y Genoveva Queipo de Llano, Alfonso XIII, el rey polémico (Madrid: Taurus, 2001), 104.
} 
señalará el diputado carlista Juan Vázquez de Mella, requiere del gobierno la consideración de "calumnia inferida al Jefe del Estado" la acusación emitida por el semanario La Hormiga de Oro al estar la Orden masónica prohibida por la religión católica, "que es la religión del Estado"38. Sigue su alocución el diputado por Cartagena reprochando al gobierno, especialmente al ministro de Gobernación Ruiz Capdepón, titular de la cartera de Gracia y Justicia en el momento de publicarse la supuesta iniciación de los reyes, la tardanza en la detención del autor de las proclamas, José Domingo Corbató, pues hasta octubre no emitió la audiencia de Valencia el edicto de detención ${ }^{39}$, haciéndolo solo cuando la regente solicitó al gobierno tomar diligencias en el asunto, por lo que no le cabe ninguna duda de la desprotección del equipo gubernamental hacia la monarquía ${ }^{40}$.

En definitiva, la sola acusación es un delito, pero que lleve tintes masónicos la hace todavía más grave. A esa consideración llegaron los dos ideólogos del turnismo legitimador de la alternancia de partidos en la Restauración, Antonio Cánovas del Castillo y Práxedes Mateo Sagasta, ya que ambos hicieron constar en el registro de la sesión que la calumnia no podía ser otra cosa que un "crimen de lesa majestad" 41 . El segundo, presidente del Consejo de Ministros en aquel momento, no podría olvidar, a lo largo del debate parlamentario sobre la iniciación de los reyes, su vinculación con la masonería en el pasado, y, si por casualidad se le había borrado de la mente, el carlista Vázquez de Mella hubo de recordárselo, consiguiendo de Sagasta la afirmación de su pasada pertenencia a la Orden, de la cual se apartó, sabedor de su legalidad, pues él llevo a cabo la ley de 1887, al conocer las condenas papales, incompatibles con ser masón y buen católico al mismo tiempo ${ }^{42}$. Para los anales de la Historia del parlamentarismo español ha quedado la contundente respuesta de Vázquez de Mella, que sin duda sirvió para dejar en evidencia al político liberal con su anterior afirmación: "no hay un solo Papa del siglo XIX que no haya condenado a la masonería", y el señor Sagasta ha tardado "ochenta años en enterarse"43.

Por tanto, señalada y reafirmada la falsedad de la noticia que pretendía hacer de los monarcas españoles masones operantes en logias al servicio de los organismos masónicos europeos, la Orden podía volver a respirar tranquila, aunque no por mucho tiempo, pues la agitación colonial estaba a la vuelta de la esquina. A partir de entonces, el mito de la antiespañolidad de la masonería, si hasta ahora estaba en formación, con el Desastre del 98 pasará a convertirse en un hecho.

\footnotetext{
${ }^{38}$ Diario de Sesiones del Congreso de los Diputados de España (Madrid, 14 de noviembre de 1894): 23-24.

${ }^{39}$ Canal, "Los instrumentos del infierno", 62-64.

${ }^{40}$ Diario de Sesiones del Congreso de los Diputados de España (Madrid, 14 de noviembre de 1894): $24-26$.

${ }^{41}$ Diario de Sesiones del Congreso de los Diputados de España (Madrid, 14 de noviembre de 1894): 26-27.

42 Alvarado Planas, Masones en la nobleza de España, 272.

${ }^{43}$ Diario de Sesiones del Congreso de los Diputados de España (Madrid, 14 de noviembre de 1894): 28.
} 


\section{8 y la pérdida de las colonias, ¿complot masónico contra el país?}

En 1891 recibía Fernando Lozano Montes, ilustre masón y librepensador, numerosas cartas de agradecimiento llegadas de diversas logias del territorio nacional ${ }^{44}$. La defensa de la masonería contra los ataques clericales en la revista de la que era cofundador, Las Dominicales del Librepensamiento, le había servido para catapultarse a la fama del pensamiento libre y moderno en España. Gracias a este prestigio, pudo ser representante de la masonería en el Congreso Internacional de Librepensadores, conmemoración del cuarto centenario de la llegada española a América, que iba a celebrarse en Madrid en 1892. La suspensión del evento el mismo día de su apertura, 12 de octubre, mediante orden emitida por Cánovas del Castillo ${ }^{45}$, iba a ser buena prueba de la censura del gobierno en todo lo relacionado con las colonias, más si estos certámenes podían contribuir a desestabilizar el maltrecho estatus colonial del país al abordarse en los mismos la cuestión del independentismo, consideración harto difusa pues con la celebración del Descubrimiento la masonería no dejaba de hacer gala de su españolismo ${ }^{46}$.

Los sucesos coloniales comenzaron tres años antes del famoso Desastre, en 1895. Iniciados los disturbios en Cuba y más tarde la insurrección en Filipinas, el Partido Liberal de Sagasta, por entonces en el gobierno, se lanzó a acusar a la masonería de filibusterismo y de presunta participación en favor de la independencia ${ }^{47}$. Inmediatamente comenzados los hechos, y a tenor de lo dispuesto en el Código Penal de 1870, multitud de logias de distintas obediencias eran asaltadas por las fuerzas de orden público, viéndose obligada la institución a clausurar sus puertas por orden del gobernador de Madrid. Pronto el decreto se hacía efectivo a todos los puntos del territorio nacional, fueran parte de la metrópoli o de las colonias; la vida masónica era interrumpida en España, fuese cual fuese la obediencia, hasta inicios del siglo $\mathrm{XX}^{48}$. Ello iba a suponer un duro golpe para la masonería hispana, perdiendo todo tipo de capacidad operativa, así como gran cantidad de hermanos entre sus filas, descendiendo el número de los mismos durante el período 1900-1939 hasta los 5.000 masones inscritos en 229 logias, cifras irrisorias en comparación a los 82.000 masones y 1.750 logias operativas entre 1868 y $1900^{49}$.

\footnotetext{
${ }^{44}$ Las logias "Hijos de la Verdad", de Jaén, "Puritanos", de Madrid, y "Unión Latina", de Cuba, son algunos de los muchos templos que honran la figura de Lozano por su artículo titulado Mi Discurso. En él se hace una defensa integra de la Orden, combatiéndose "el error y la superstición". Véase Centro Documental de la Memoria Histórica [CDMH], "Masonería, Sección Especial”, leg. no. 56-A, exp. no. 2.

${ }^{45}$ María José Villegas Sanz, "Aproximación a la ideología de los talleres masónicos madrileños del siglo XIX", en La masonería en la España del siglo XIX, coord. Ferrer Benimeli (Valladolid: CEHME, 1987), tomo II, 547.

${ }^{46}$ Alvarado Planas, Masones en la nobleza de España, 204.

${ }^{47}$ Ferrer Benimeli, "España y el Congreso Antimasónico de Trento", en La masonería española y la crisis colonial del 98, coord. Ferrer Benimeli (Zaragoza: CEHME, 1999), tomo I, 279.

${ }^{48}$ Alvarado Planas, Masones en la nobleza de España, 34-35.

${ }^{49}$ Pere Sánchez Ferré, La masonería y los masones españoles del siglo XX: los pasos perdidos (Barcelona: Mra, 2012), 17.
} 
Pero ¿fue la Orden del Gran Arquitecto del Universo la principal responsable de la pérdida de los últimos territorios ultramarinos desencadenantes del famoso Desastre de 1898? La respuesta a esta pregunta ha sido ampliamente difundida por historiadores y estudiosos de la institución masónica como José Antonio Ferrer Benimeli, Manuel de Paz Sánchez ${ }^{50}$ y Javier Alvarado Planas. Ellos afirman que la masonería española, aun siendo partidaria del autonomismo y firme rival del clericalismo existente en algunos territorios, jamás se mostró a favor de la independencia colonial, apostando por un españolismo intachable ${ }^{51}$. Sin embargo, la torpe actuación de Miguel Morayta, siempre dispuesto a actuar en favor de Filipinas, hizo que tanto la institución eclesiástica como el conservadurismo político trabajaran conjuntamente para construir el mito del anti-españolismo de la masonería, pues para ellos eran las actividades llevadas a cabo por el Gran Maestre las causantes de la insurrección en el archipiélago ${ }^{52}$. En consecuencia, se propagará el paradigma del complot masónico contra el país. En el intervendrá esta sociedad secreta, "traidora a todas luces", "organización antipatriótica que trabajaba contra España"53.

Si la cuestión de la supuesta iniciación de los monarcas españoles en la masonería llegó a las Cortes ante la resonancia mediática del episodio, no iba a ser menos con la pérdida de las colonias, suceso que sin duda pondrá en jaque la conciencia nacional del país durante las primeras décadas del nuevo siglo. En 1904, seis años después del Desastre, Miguel Morayta, la persona a la cabeza de la masonería hispana durante las últimas dos décadas se verá de nuevo obligado a intervenir en su defensa. Ocurrió el día en el cual se debatía en Cortes la provisión de la silla episcopal de Valencia en favor del padre Nozaleda, antiguo dominico y arzobispo de Manila, territorio en el que se mantuvo después de la derrota colonial. La decisión de removerlo hacia la península formaba parte de la estrategia llevada a cabo por Antonio Maura en su primera etapa al frente del gobierno, pieza clave del conservadurismo español en el siglo $\mathrm{XX}^{54}$. Como cabeza del ejecutivo, Maura formulaba tal disposición con el objetivo de instaurar al religioso en uno de los focos más fuertes del republicanismo blasquista; el político, baluarte de la Iglesia y el clericalismo, ponía en práctica lo que se ha llamado su "revolución desde arriba" 55 . A estas alturas, y a tenor de lo ocurrido desde 1898, la sociedad española ya estaba polarizada frente a dos tendencias. De un lado, la confesional, con Maura y el Partido Conservador a la cabeza. Por otro, la

\footnotetext{
${ }^{50}$ El historiador Manuel de Paz Sánchez ha ofrecido un riguroso estudio sobre el verdadero papel de la masonería en la pérdida de las colonias libre de mitos y falsas implicaciones. Véase Manuel de Paz Sánchez, La masonería y la pérdida de las colonias. Estudios (Santa Cruz de Tenerife: Ediciones Idea, 2006).

${ }^{51}$ Alvarado Planas, Masones en la nobleza de España, 205-206.

${ }^{52}$ María Asunción Ortiz de Andrés, Masonería y democracia en el siglo XIX: el gran oriente español y su proyección político-social (1888-1896) (Madrid: Universidad Pontificia Comillas, 1993), 325-326.

53 Abilio Jorge Torres, La masonería en la sociedad riojana, 1869-1939 (Logroño: Instituto de Estudios Riojanos, 2015), 75.

${ }^{54}$ María Jesús González Hernández, Ciudadanía y acción: el conservadurismo maurista, 1907-1923 (Madrid: Siglo XXI, 1990), 126-133.

${ }^{55}$ Suárez Cortina, La España liberal (1868-1917): política y sociedad (Madrid: Síntesis, 2006), 206-207.
} 
secularizadora, formando parte de esta un conglomerado de fuerzas políticas que van desde el liberalismo hasta el republicanismo, aglutinando todas ellas a masones entre sus filas ${ }^{56}$.

Parece que Morayta eligió decantarse por la nominación del eclesiástico para defender a la Orden debido a un doble motivo. Además de protegerse de las acusaciones de Maura que culpaban a la masonería de todo lo ocurrido en 1898, el Gran Maestre no había olvidado que Nozaleda fue la persona que hizo caer en desgracia a Ramón Blanco, Capitán General de Cuba y más tarde de Filipinas, vilipendiado políticamente ante las acusaciones de pertenencia a la masonería por parte del clérigo sin haber estado nunca entre sus filas ${ }^{57}$. Comenzó su alocución el masón y diputado republicano haciendo constar el desprecio personal del presidente Maura tanto por su persona ${ }^{58}$ como por la Orden, a la cual su partido y los medios de comunicación afines culpaban de los sucesos coloniales, llegando incluso a rivalizar por ello con el líder de las Cortes Francisco Romero Robledo ${ }^{59}$. El objetivo de Morayta con su discurso es claro, terminar "con una leyenda, la leyenda de la masonería", ya que ésta viene siendo desde 1887 una "asociación perfectamente legal", y por tanto falsa la acusación de filibusterismo y antiespañolismo de los hermanos filipinos dependientes del GOE, pues ellos, como requisito para pertenecer a la Orden, debían tener una posición social cómoda y mostrar amor al país, quedando perfectamente probado "su españolismo"60.

Con todo, las palabras del dirigente masón estaban diciendo basta al mito de antiespañolidad de la masonería formalmente construido a raíz de los sucesos coloniales. Sin embargo, de poco le iba a servir presentar a la familia masónica como una institución "muy seria y muy española". Cuando Franco, 36 años más tarde y a la cabeza del nuevo régimen, publique la ley para reprimir a la masonería y el comunismo, no iba a tener ninguna duda de la responsabilidad de la Orden "en la pérdida del imperio colonial español" ${ }^{61}$. La jerarquía eclesiástica, los medios de comunicación, el Desastre de 1898 y los políticos españoles, desde Cánovas hasta Sagasta y Maura, le ponían en bandeja al caudillo argumentos sesgados del pasado para legitimar la prohibición de la "secta" en el presente y futuro de su dictadura.

\footnotetext{
${ }^{56}$ Suárez Cortina, La España liberal, 165.

${ }^{57}$ Alvarado Planas, Masones en la nobleza de España, 220-221.

${ }^{58}$ Días antes de la sesión de Cortes, parece que Maura había señalado en público y "con soberano arte" un saludo recibido por parte de Morayta de la tal forma que, en opinión del primero, "parecía que aún le quemaba la diestra que le tendiera". Diario de Sesiones del Congreso de los Diputados de España, no. 115 (Madrid, 1 de febrero de 1904): 3589.

${ }^{59}$ Por como aparece recogido en el diario de sesiones el diálogo mantenido por Romero Robledo y Morayta, parece que el primero, dentro de su pensamiento católico y conservador, consideraba como algo mal visto socialmente, o si se quiere, por ajustarlo al contexto, parlamentariamente, la pertenencia no solo de Morayta, sino de cualquier persona, a la masonería. Diario de Sesiones del Congreso de los Diputados de España, no. 115,3591 .

${ }^{60}$ Diario de Sesiones del Congreso de los Diputados de España, no. 115 (Madrid, 1 de febrero de 1904): 3594.

${ }^{61}$ Boletín Oficial del Estado [BOE], "Ley de 1 de Marzo de 1940 Sobre Represión de la Masonería y del Comunismo", 1537.
} 


\section{Los tiempos de la Gran Guerra. Por la paz y con la democracia}

1917 fue una fecha muy significativa en el engrandecimiento del mito anti-español de la Orden. Además de ser el año de fallecimiento de Miguel Morayta, la persona que más había protegido y defendido a la Orden masónica desde 1889, fue el momento en el cual llegó a España un triple conflicto militar, político y social derivado de la Primera Guerra Mundial y de la incapacidad y debilidad del sistema de la Restauración para seguir funcionando tal y como había sido planeado después del turnismo ${ }^{62}$.

La masonería, una vez iniciada la contienda bélica que tuvo al mundo en vilo durante casi cuatro cruentos años, se declararía, del mismo modo que el gobierno conservador de Eduardo Dato, neutral. Pesó sobre esta decisión la tradición masónica, pues según Anderson y sus constituciones la Orden del Gran Arquitecto del Universo no podía ir en contra de lo así dispuesto por los gobernantes del país. Del mismo modo, también contribuía en su decisión las consignas de paz y neutralidad expresadas por uno de los principales organismos masónicos mundiales, el Bureau Internacional de Relaciones Masónicas, situado en Suiza ${ }^{63}$. Sin embargo, las disensiones habidas dentro de la familia masónica, especialmente aquellas relacionadas con Cataluña y su papel territorial dentro de España, llevaron a que la Gran Logia Simbólica Regional Catalana Balear (GLSRCB), federada dentro del GOE, obligase a la obediencia a decantarse, con el devenir de la guerra, por la causa aliadófila ${ }^{64}$. Naturalmente, también pesaba sobre dicha forma de actuar el carácter político del sustituto de Morayta al frente del GOE, Luis Simarro, militante republicano en el Partido Reformista de Melquíades Álvarez ${ }^{65}$, organización política que, además de contar con muchos masones entre sus filas, se había declarado, como todos las organizaciones republicanas, a favor de la causa aliada, pues su triunfo político en el interior del país dependía de la derrota del eje ${ }^{66}$, a quien había condenado como ejemplo del despotismo negador de toda libertad por llevar a cabo un gran número de atrocidades contra el enemigo no pasadas por alto en otra "guerra", la mantenida por la opinión pública ${ }^{67}$.

De los tres conflictos acaecidos en la famosa crisis del verano de 1917, trataremos aquí los que tuvieron una índole puramente política y social, en los cuales la masonería estuvo implicada activamente. Desencadenada en junio la rebelión militar en forma de juntas, donde los militares solicitaban del gobierno una mayor compensación económica por la dureza de

\footnotetext{
${ }^{62}$ González Hernández, Ciudadanía y acción, 68-69.

${ }^{63}$ Sánchez Ferré, La masonería, 45.

${ }^{64}$ Sánchez Ferré, La masonería, 46.

${ }^{65}$ María Dolores Gómez Molleda, La masonería en la crisis española del siglo XX (Madrid: Taurus, 1986), 30.

${ }^{66}$ Suárez Cortina, El reformismo en España: republicanos y reformistas bajo la monarquía de Alfonso XIII (Madrid: Siglo XXI, 1986), 151.

${ }^{67}$ Guillermo J. Pérez Casanova. "Raemaekers y Picarol: la imagen del ejército alemán en la Gran Guerra desde una perspectiva aliadófila", en La guerra: retórica y propaganda (1860-1970), coords. Fidel Gómez Ochoa, José Goñi Pérez y Daniel Macías Fernández (Madrid: Biblioteca Nueva, 2014), 121.
} 
la guerra en el Protectorado y un trato igualitario en función del destino de los soldados, fuese éste las guarniciones africanas o interiores ${ }^{68}$, estuvo seguida por la formación de una Asamblea de Parlamentarios republicanos, catalanistas y socialistas, quienes actuaban tanto como reacción al problema militar como para exigir una reforma constitucional que diera al país una apariencia democrática no conseguida por los gobiernos alternantes en el sistema político. Tal intento de transformación, llevado a cabo por los partidos opositores al régimen y auspiciado por el común acuerdo de estos al defender la causa aliada en la contienda mundial, parecía tener como objetivo la reforma de la Constitución de 1876 en base a postulados federalistas ${ }^{69}$.

Iniciada la actividad de los parlamentarios, la masonería española, con el GOE y Luis Simarro a la cabeza, quiso llevar la situación con la misma calma de 1914, una vez declaradas las hostilidades en la guerra. Sin embargo, al igual que ocurriera entonces, la GLSRCB decidió actuar por su cuenta y sumarse al acontecimiento junto con los opositores al régimen ante la iniciativa catalanista y la celebración de la Asamblea en Barcelona el 19 de julio ${ }^{70}$. Ello llevaría, tal y como ocurrió en el pasado, al GOE a decantarse por el apoyo a los parlamentarios a través del visto bueno personal del Gran Maestre Simarro y mediante la formación, en el mes de septiembre, de una comisión encargada de auxiliar económicamente a los presos del movimiento democratizador y de la ulterior huelga de agosto ${ }^{71}$.

Las consecuencias para la Orden después de apoyar la intentona reformista del régimen no fueron muy distintas de las acaecidas en el pasado. Desde agosto de 1917 tuvieron que suspender tenidas y trabajos debido a que muchos medios de comunicación y miembros del gobierno les culpaban de participar en los hechos, no volviéndose a ver indicios de actividad masónica hasta ya comenzado $1918^{72}$. Si bien, puede afirmarse que, ante los ojos de las clases medias y de muchos intelectuales, la masonería consiguió ganar un prestigio perdido por muchos partidos políticos, siendo a partir de entonces cuando comiencen a iniciarse en ella personalidades de todos los planos de la política y cultura españolas que van a estar llamados a tener un importante papel en el devenir histórico de España, bien sea, primero, como oposición a la Dictadura de Primo de Rivera, o como firmes partidarios de la llegada de la república, después ${ }^{73}$.

Con todo, la activa participación de la Orden en los sucesos de 1917 iba a costarle lo poco que le quedaba de regularidad masónica en casi toda su extensión, es decir, el claro

\footnotetext{
${ }^{68}$ Hall, Alfonso XIII y el ocaso, 202-207.

${ }^{69}$ Suárez Cortina, La España liberal, 196-199.

${ }^{70}$ Gómez Molleda, La masonería, 30.

${ }^{71}$ Con respecto al comité que organizó la huelga de agosto, una comisión masónica del GOE formada por Ceferino González Castroverde y Pedro Rico se encargó de visitar y atender las demandas de los presos una vez encarcelados. Véase Luis P. Martín, Los arquitectos de la república: los masones y la política en España, 1900-1936 (Madrid: Marcial Pons, 2007), 69-70.

${ }^{72}$ Gómez Molleda, La masonería, 32.

${ }^{73}$ Martín, Los arquitectos, 39-40.
} 
abandono de los postulados históricos legitimadores de su existencia desde el siglo XVIII pasando de este modo a tener un papel muy activo en los acontecimientos políticos del país sin ser por ello una formación con tales tintes. La declaración de que la masonería debía ser "la casa política de todas las izquierdas" dictaminada por el GOE en su Gran Asamblea de 1918 y la superación de problemas internos una vez llegado el régimen primorriverista iban a servirle a Franco, del mismo modo que las condenas papales, los sucesos coloniales de 1898 y la situación en la república y posterior guerra, para constatar la tesis de que la masonería no podía formar parte del proyecto de España planteado por él durante los 36 años de su gobierno, desde 1939 hasta 1975. Pasaban a ser los masones, como tantos republicanos, anarquistas, socialistas y comunistas, tan unidos en la diversidad, los símbolos principales de la anti-España.

\section{Conclusiones}

Pertenecer a una sociedad o asociación como la masonería durante los años que distan entre el fracaso de la Primera República y el golpe de mano de Miguel Primo de Rivera en septiembre de 1923 fue una tarea difícil para los miles de masones que decidieron adentrarse en la vida iniciática una vez construido y consolidado el régimen político de la Restauración Borbónica (1874-1923). A pesar de ser éste un periodo de la historia española sin precedentes en el desarrollo y la profusión de los ideales masónicos por todo el territorio nacional, también florecieron, con el objetivo de contrarrestar su impulso, una serie de mitologemas que venían a desprestigiar las verdaderas obras y metas de la masonería.

En las pasadas páginas hemos decidido centrarnos en uno en particular: el falso mito que presenta a la Orden masónica como una institución anti-española al haber intervenido contra la estabilidad del sistema siendo la principal responsable de sucesos políticos como la pérdida de los últimos vestigios coloniales en 1898, o de disturbios sociales que se manifestaron en forma de revueltas, revoluciones, reuniones de parlamentarios y huelgas generales. La génesis de esta teoría fue posible gracias a diversos agentes de la realidad hispana que trabajaron incansablemente en su aparición, empezando por la iglesia y la monarquía, los grandes poderes del momento, quienes contaron con la inestimable ayuda de gobiernos encabezados por Antonio Cánovas del Castillo, Práxedes Mateo Sagasta o Antonio Maura, y de multitud de obras y artículos periodísticos firmados por autores cuyas ideologías políticas iban desde el integrismo hasta el conservadurismo. En tales circunstancias, la publicación años más tarde, hacia 1940, de la Ley para la Represión de la Masonería y el Comunismo, no era más que una compilación, adaptada a la nueva realidad política salida de la Guerra Civil, de los ataques y falsas acusaciones que rodearon a la Orden del Gran Arquitecto del Universo en los tiempos del sistema canovista. 


\section{Fuentes}

Encíclica Humanum Genus, Vaticano, 1884.

Gaceta de Madrid, "Ley de Asociaciones de 1887”, Madrid, 1887.

La Luz de la Verdad, Madrid, 1891.

Boletín Oficial del Grande Oriente Español [BOGOE], Madrid, 1894.

Diario de Sesiones del Congreso de los Diputados de España, Madrid, 14 de noviembre de 1894.

Diario de Sesiones del Congreso de los Diputados de España, Madrid, 1 de febrero de 1904. Boletín Oficial del Estado [BOE], "Ley de 1 de Marzo de 1940 Sobre Represión de la Masonería y del Comunismo", Madrid, 1940.

Centro Documental de la Memoria Histórica [CDMH], "Masonería, Sección Especial”, Leg. no. 56-A, Exp. no. 2.

\section{Bibliografía}

Alvarado Planas, Javier. Masones en la nobleza de España, una hermandad de iluminados. Madrid: La Esfera de los Libros, 2016.

Álvarez Junco, José. Mater dolorosa, la idea de España en el siglo XIX. Barcelona: Taurus, 2001.

Arbeloa, Víctor Manuel. Clericalismo y anticlericalismo en España (1767-1930), una introducción. Madrid: Editorial Encuentro, 2009.

Azaña Díaz, Manuel. Memorias políticas y de guerra. Barcelona: Crítica, 1981.

Canal, Jordi. "Los instrumentos del infierno: masonería y judaísmo en la prensa carlista a finales del siglo XIX”. En La masonería española en la época de sagasta. Coordinado por José Antonio Ferrer Benimeli. Zaragoza: CEHME, 2007.

Cueva Merino, Julio. De la. Clericales y anticlericales: el conflicto entre confesionalidady secularización en Cantabria (1875-1923). Santander: Universidad de Cantabria, 1994.

Domínguez Arribas, Javier. “Juan Tusquets y sus ediciones antisectarias (1936-1939)”. En La masonería española en la época de sagasta. Coordinado por José Antonio Ferrer Benimeli. Zaragoza: CEHME, 2007.

Duarte, Ángel. El republicanismo: una pasión política. Madrid: Ediciones Cátedra, 2013.

Escudero, José Antonio. "Las sociedades secretas ante la legislación española del siglo XIX”. En Masonería, política y sociedad. Coordinado por José Antonio Ferrer Benimeli. Zaragoza: CEHME, 1989.

Ferrer Benimeli, José Antonio. La masonería actual. Barcelona: Editorial AHR, 1977. 
Ferrer Benimeli, José Antonio. "España y el Congreso Antimasónico de Trento". En La masonería española y la crisis colonial del 98. Coordinado por José Antonio Ferrer Benimeli. Zaragoza: CEHME, 1999.

Ferrer Benimeli, José Antonio. "Práxedes Mateo-Sagasta, gran maestre de la masonería”. En La masonería española en la época de sagasta. Coordinado por José Antonio Ferrer Benimeli. Zaragoza: CEHME, 2007.

Ferrer Benimeli, José Antonio. "El krausoinstitucionismo, la masonería y el librepensamiento". En Libertad, armonía y tolerancia: la cultura institucionista en la España contemporánea. Coordinado por Manuel Suárez Cortina. Madrid: Editorial Tecnos, 2011.

Gómez Molleda, María Dolores. La masonería en la crisis española del siglo XX. Madrid: Taurus, 1986.

González Hernández, María Jesús. Ciudadanía y acción: el conservadurismo maurista, 1907-1923. Madrid: Siglo XXI, 1990.

Hall, Morgan C. Alfonso XIII y el ocaso de la monarquía liberal, 1902-1923. Madrid: Alianza Editorial, 2005.

Hidalgo Nieto, Victoria. "Masonería y libertad de asociación". En La masonería en la España del siglo XIX. Coordinado por José Antonio Ferrer Benimeli. Salamanca: CEHME, 1987.

Jorge Torres, Abilio. La masonería en la sociedad riojana, 1869-1939. Logroño: Instituto de Estudios Riojanos, 2015.

Juliá, Santos. Historias de las dos Españas. Madrid: Taurus, 2004.

Martín, Luis P. Los arquitectos de la república: los masones y la política en España, 19001936. Madrid: Marcial Pons Historia, 2007.

Ortiz de Andrés, María Asunción. Masonería y democracia en el siglo XIX: el gran oriente español y su proyección político-social (1888-1896). Madrid: Universidad Pontificia Comillas, 1993.

Paz Sánchez, Manuel de. La masonería y la pérdida de las colonias. Estudios. Santa Cruz de Tenerife: Ediciones Idea, 2006.

Pérez Casanova, Guillermo J. "Raemaekers y Picarol: la imagen del ejército alemán en la Gran Guerra desde una perspectiva aliadófila”. En La guerra: retórica y propaganda (1860-1970). Coordinado por Fidel Gómez Ochoa, José Goñi Pérez y Daniel Macías Fernández. Madrid: Biblioteca Nueva, 2014.

Preston, Paul. El holocausto español: odio y exterminio en la guerra civil y después. Barcelona: Debate, 2017.

Sánchez Ferré, Pere. La masonería y los masones españoles del siglo XX: los pasos perdidos. Barcelona: Ediciones mra, 2012.

Suárez Cortina, Manuel. El reformismo en España: republicanos y reformistas bajo la monarquía de Alfonso XIII. Madrid: Siglo XXI, 1986. 
Suárez Cortina, Manuel. El gorro frigio: liberalismo, democracia y republicanismo en la restauración. Madrid: Sociedad Menéndez Pelayo, 2000.

Suárez Cortina, Manuel. La España liberal (1868-1917): política y sociedad. Madrid: Editorial Síntesis, 2006.

Suárez Cortina, Manuel. Entre cirios y garrotes: política y religión en la España contemporánea, 1808-1936. Santander: Editorial de la Universidad de Cantabria, 2014.

Tusell, Javier y Queipo de Llano, Genoveva G. Alfonso XIII, el rey polémico. Madrid: Taurus, 2001.

Tusquets, Juan. La francmasonería, crimen de lesa patria. Burgos: Ediciones Antisectarias, 1936.

Villegas Sanz, Mo José. "Aproximación a la ideología de los talleres masónicos madrileños del siglo XIX”. En La masonería en la España del siglo XIX. Coordinado por José Antonio Ferrer Benimeli. Valladolid: CEHME, 1987.

Zulueta, Luis de. La oración del incrédulo: ensayos sobre el problema religioso. Madrid: Biblioteca Nueva, 1915. 